Revista "Política y Estrategia" № 135, 2020, pp. 99-126

ISSN 0716-7415 (versión impresa) - ISSN 0719-8027 (versión en línea)

Academia Nacional de Estudios Políticos y Estratégicos

Fortalecimiento de la capacidad operativa de las FF.AA. frente a catástrofes y emergencias: el potencial olvidado de la Defensa Civil

Anita Perricone

\title{
FORTALECIMIENTO DE LA CAPACIDAD OPERATIVA DE LAS FF.AA. FRENTE A CATÁSTROFES Y EMERGENCIAS: EL POTENCIAL OLVIDADO

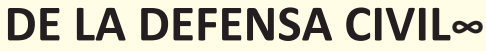

\section{ANITA PERRICONE'}

\begin{abstract}
RESUMEN
Este artículo plantea que la Defensa Civil, organismo que depende del Ministerio de Defensa Nacional (MDN), podría contribuir al fortalecimiento de la capacidad operativa de las FF.AA. en el ámbito de la gestión del riesgo de desastres, catástrofes y emergencias. Sin embargo, en la actualidad, el organismo carece de financiamiento y no está incluido en la planificación político-estratégica del MDN en lo que concierne la intervención en dichos escenarios, ni en el Plan Nacional de Protección Civil. Se partirá por ilustrar los problemas que afectan a la Defensa Civil en la actualidad, para luego analizar el rol que el sector de la defensa ha ido asumiendo en la intervención en desastres, bajo el alero de tratados internacionales suscritos por Chile. Se concluirá que dotar a la Defensa Civil de un rol de apoyo a la labor desempeñada por las FF.AA. en situaciones de emergencia, desastre o catástrofe sería clave para suplir el vacío dejado por la falta de un brazo operativo a disposición de la Oficina Nacional de Emergencias (ONEMI) del Ministerio del Interior.
\end{abstract}

Palabras clave: Defensa civil; gestión del riesgo de desastre; capacidad operativa; FF.AA.; protección civil.

\section{STRENGTHENING THE OPERATIONAL CAPACITY OF THE ARMEDS IN THE FACE OF DISASTERS AND EMERGENCIES: THE FORGOTTEN POTENTIAL OF CIVIL DEFENSE}

\footnotetext{
ABSTRACT

This article argues that Civil Defense, an agency that depends on the Ministry of National Defense (MDN), could contribute to strengthening the Armed Forces' operational capacity in the field of disaster risk management. However, the agency lacks funding and is excluded from

× Fecha de recepción: 050919 - Fecha de aceptación: 130820

- Licenciatura en Desarrollo y cooperación internacional (2004-2007), Minor en Sociología, Facultad de Ciencias Políticas, Universitá degli Studi di Bologna, Italia. Magíster en Estudios europeos e internacionales (2008-2011), Minor en protección y promoción de los DDHH, School of International Studies, Universitá degli Studi di Trento, Italia. Magíster en Ciencia Política, Instituto de Ciencia Política, Primera área: Relaciones internacionales, Segunda área: política comparada, Pontificia Universidad Católica de Chile (2012- 2014). Doctorado en Ciencia Política, Instituto de Ciencia Política, Pontificia Universidad Católica de Chile. perricone.a@gmail.com ORCID: https://orcid.org/0000-0003-0715-4750.
} 
the Ministry's political and strategic planning regarding disaster and emergency intervention, as well as from the National Civil Protection Plan. The article illustrates the problems currently affecting Civil Defense, analyzing the role that the defense sector already assumed in disaster intervention, in obedience to international treaties subscribed by Chile. It is argued that providing the Civil Defense with the task of assisting the Armed Forces in emergency situations would be key to fill in the gap left by the absence of an operative task-force at the disposal of the National Office for Emergencies (ONEMI) of the Ministry of Interior.

Key words: Civil defense; disaster risk management; operative capacity; armed forces; civil protection.

\title{
FORTALECENDO A CAPACIDADE OPERACIONAL DOS BRAÇOS DIANTE DOS DESASTRES E DAS EMERGÊNCIAS: O POTENCIAL ESQUECIDO DA DEFESA CIVIL
}

\section{RESUMO}

\begin{abstract}
Este artigo argumenta que a Defesa Civil, uma agência que depende do Ministério da Defesa Nacional (MDN), poderia contribuir para fortalecer no campo da gestão de riscos a capacidade operativa das Forças Armadas na intervenção em desastres. No entanto, a agência carece de financiamento e está excluída do planejamento político e estratégico do Ministério em relação a desastres e intervenções de emergência, bem como do Plano Nacional de Proteção Civil. O artigo ilustra os problemas que atualmente afetam a Defesa Civil, analisando o papel que o setor de defesa está gradualmente assumindo na intervenção em desastres, na obediência aos tratados internacionais assinados pelo Chile. Argumenta-se que fornecer à Defesa Civil a tarefa de auxiliar as forças armadas em situações de emergência seria essencial para preencher a lacuna deixada pela ausência de uma forçatarefa operacional à disposição do Escritório Nacional de Emergências (ONEMI) do Ministério do Interior.
\end{abstract}

Palavras-chave: Defesa Civil; gerenciamento de riscos de desastres; capacidade operativa; forças armadas; proteção civil.

\section{INTRODUCCIÓN}

Chile es un país altamente expuesto a desastres de origen tanto natural como antrópico, que inexorablemente afectan a las personas, sus bienes y al medio ambiente. Terremotos, tsunamis, temporales, aluviones, erupciones volcánicas son solo algunas de las amenazas que vuelven a la población chilena un conjunto de comunidades potencialmente vulnerables. A estos factores se agregan, en 2020, los desafíos que la pandemia protagonizada por el nuevo Coronavirus (COVID-19) plantea para la salud pública nacional, y que desnudan a Chile y al sector de la seguridad en toda su vulnerabilidad. 
Esta fragilidad se ve acrecentada por el aumento de las calamidades naturales producto de los efectos del cambio climático, y de la globalización que, al relativizar las fronteras, incrementa la exposición de los países a los factores de riesgo globales.

En Chile, como en cualquier otro país, esta condición es susceptible de ser superada solo y exclusivamente con el apoyo de una institucionalidad fuerte, respaldada por el cumplimiento de los compromisos internacionales suscritos en materia de gestión del riesgo de desastres (GRD). Entre los acuerdos internacionales en esta materia destacan el Marco de Acción de Hyogo (2005-2015) y el Marco de Sendai (2015-2030). El primero tuvo como objetivo garantizar que la reducción del riesgo de desastres (RRD) se convirtiera en una prioridad para las autoridades, tanto nacionales como locales, y que ésta contara, en todos los países suscriptores, con una institucionalidad adecuada. El segundo apunta a fortalecer las capacidades de los Estados en la GRD, y en particular los aspectos relacionados con una mejor comprensión del riesgo, con el fortalecimiento de la gobernanza, de la resiliencia y de las capacidades que requiere la fase de reconstrucción.

Frente a la exposición de la población chilena a los riesgos antes mencionados, el Estado de Chile se ha preparado para intervenir en apoyo de la ciudadanía. El marco legal en el cual dicho apoyo fue proporcionado tiene como fundamento el Artículo $1^{\circ}$, Capítulo I de la Constitución Política de la República, que en su inciso $5^{\circ}$ afirma que: "Es deber del Estado resguardar la seguridad nacional, dar protección a la población y a la familia (...)". Para poder cumplir con dichas funciones, el Estado les ha otorgado competencias a distintos órganos de la Administración del Estado. Las principales atribuciones, en lo que concierne a la Protección Civil, le competen al Ministerio del Interior y Seguridad Pública, a través de la Oficina Nacional de Emergencias (en adelante, ONEMI), instituida en 1974 a través del $\mathrm{DL} \mathrm{N}{ }^{\circ}$ 369. La creación de dicha agencia no fue la primera medida tomada por el Estado para abordar las necesidades de protección de la población frente a amenazas de distinta índole, ni la última. Sin embargo, la creación de la ONEMI fue determinante en los desarrollos que conciernen la Defensa Civil de Chile, que constituye el objeto de estudio de este capítulo.

¿Qué rol cumple la Defensa Civil en la actualidad? ¿Qué problemáticas la afectan? ¿De qué manera podría contribuir al fortalecimiento de la capacidad operativa de las FF.AA. en el marco del SNPC? Este artículo tiene como objetivo general justificar la conveniencia de potenciar el rol de la Defensa Civil de manera que pueda aportar de forma más contundente al Sistema Nacional de Protección Civil. Con dicho objetivo en mente, se procederá de la forma detallada a continuación: en la siguiente sección se revisarán los orígenes, misión y funciones, y problemáticas que afectan a la Defensa Civil en la actualidad; en segundo lugar se analizará la evolución del Sistema Nacional de Protección Civil (SNPC); en tercer lugar se detallará el marco legal que regula la participación del sector de la defensa en el SNPC; en cuarto lugar se revisará la experiencia comparada; y en quinto lugar se visualizarán distintas opciones que viabilizarían el fortalecimiento de la Defensa Civil para que esta pueda incrementar la capacidad operativa de las FF.AA. en el SNPC. 


\subsection{LOS ORÍGENES DE LA DEFENSA CIVIL}

Una nueva organización nace cuando se presentan necesidades que aún no están cubiertas. Así, por ejemplo, la Federación Internacional de la Cruz Roja (FICR) se creó en 1918 en respuesta a la pandemia de la influenza española, que mató entre 50 y 100 millones de personas ${ }^{1}$. El origen de la Defensa Civil también radica en el viejo continente, y específicamente en la experiencia traumática que la Primera Guerra Mundial significó para la mayoría de los países involucrados. Dicho conflicto bélico resultó devastador en término de pérdida de vidas humanas, y mostró la necesidad de contar con una organización que supliera las funciones que ni el Estado ni las Fuerzas Armadas estaban en condiciones de desempeñar. Cuando estalló la Segunda Guerra Mundial, ya eran varios los países que contaban con organizaciones de voluntarios que estaban en condiciones de intervenir en beneficio de la población civil, cumpliendo funciones de primeros auxilios, entierro de fallecidos, entre otras.

La trayectoria histórica de la Defensa Civil de Chile comenzó en los años cuarenta, cuando el país se encontraba aún desprovisto de una organización que estuviese a disposición de la autoridad para apoyar a la población ante la ocurrencia de un desastre o de una catástrofe, ya sea de origen natural o antrópico. Desde la etapa más temprana del proceso de constitución de la organización, que contempló la conformación de una Comisión que estudiara el funcionamiento de los sistemas de protección civil en otros países, y especialmente de aquel de Estados Unidos, se consideró oportuno convocar la asesoría de personal especializado de las distintas ramas de las Fuerzas Armadas (en adelante, FF.AA.). La Comisión mencionada, por tanto, contempló la presencia de asesores técnicos del Ejército, además de delegados de la Armada, de la Fuerza Aérea y de la Dirección General de Carabineros².

La Defensa Civil vio la luz bajo la presidencia de Juan Antonio Ríos Morales a través de la firma del Decreto $N^{\circ} 6.663$ del 2 diciembre de 1942, dispuesto por el ministro de Interior Raúl Morales Beltrami. A través de otro decreto, a principios de 1943 se nombró primer director de la Defensa Civil de Chile al capitán de ejército Raúl Aldunate Phillips, quien había conducido los primeros estudios sobre la configuración que se le daría a la institución y participado activamente de las labores de la Comisión encargada de formular una propuesta de diseño de la organización. La misión de la organización quedó fijada de la siguiente manera: "La defensa Civil de Chile es una Institución cívica que tiene por misión: prevenir, evitar, reducir y reparar los efectos de cualquier catástrofe que afecte a la población civil, ya sea que provenga de fenómenos sísmicos, incendios, inundaciones, epidemias $u$ otros siniestros o calamidades públicas, así como consecuencias de un conflicto bélico (raides aéreos, actos de sabotaje, pánicos, etc.)”3.

Aunque la Defensa Civil ya estaba plenamente conformada y funcionando, habiendo incluso sido establecida una red de Comités Locales de la Defensa Civil a lo largo de todo

1 CIFRC. "Preparación para una respuesta eficaz", disponible en línea: https://media.ifrc.org/wp-content/ uploads/sites/5/2020/02/PER-epi-considerations-07022020_SP.pdf

2 DEFENSA CIVIL DE CHILE. "Historia de la Defensa Civil de Chile", disponible en línea: https://www. defensacivil.cl/historia/

3 lbíd. 
el país, la Ley que crea la Defensa Civil de Chile recién fue aprobada en el año $1945^{4}$. Dicha ley no ha sufrido ninguna modificación desde entonces, por lo que el marco legal en el que se inserta el organismo está ampliamente obsoleto. Para dar una idea de lo absurdo del marco legal vigente, la ley que crea la Defensa Civil establece, por ejemplo, que el Director General tiene la atribución de suspender el suministro de luz eléctrica en la ciudad de Santiago por motivos de seguridad. De acuerdo con las disposiciones legales vigentes, la Defensa Civil es una corporación de derecho público, cuyo accionar ha de ejecutarse a través de la administración pública, de las instituciones militares o de la autoridad que se designe.

La noción de Defensa Civil comenzó a cambiar en el mundo conforme avanzaba el siglo, pasando de una concepción ligada a la seguridad nacional y preparación ante intervenciones militares, a una más vinculada a la protección y rescate de civiles ante fenómenos naturales. De esta forma, la Defensa Civil en nuestro país se estableció como el brazo operativo de la respuesta del Estado ante desastres naturales, al menos antes de la creación de la ONEMI en 1974; sin embargo, luego la GDR se profesionalizó gradualmente en nuestro país y la Defensa Civil quedó como una organización de voluntariado más, dentro del abanico de instituciones coordinadas por ONEMI. De esta forma comenzaría una progresiva disminución de la presencia y fortaleza de esta organización hasta nuestros días.

\subsection{MISIÓN Y FUNCIONES DE LA DEFENSA CIVIL}

Tal como señala la página web del organismo ${ }^{5}$, la misión principal de la Defensa Civil es la de "Participar con el voluntariado en tareas de educación y responsabilidad social en beneficio de la ciudadanía promoviendo actividades de prevención y respuesta ante la ocurrencia de un incidente natural y/o producto de la acción humana e incorporada como parte integrante del Sistema Nacional de Protección Civil". Desde la definición de su misión, tanto en sus inicios como en la actualidad, la Defensa Civil se constituye como un actor importante en el panorama de la GRD. El aporte de la Defensa Civil al SNPC se materializa principalmente a través de la capacitación, instrucción y entrenamiento a sus voluntarios en tareas de prevención y respuesta ante situaciones de emergencia, con la finalidad de proporcionar apoyo y cooperación a la población afectada por una emergencia.

Entre las funciones de la Defensa Civil de Chile se encuentran la recepción de acopio y distribución de la ayuda humanitaria; el mantenimiento de un sistema de enlace de telecomunicaciones permanente que respalda la red de emergencia nacional; la entrega de información útil y asesoría a las autoridades comunales y la participación en la elaboración de los planes de emergencia en el marco de los Comités de Protección Civil (en adelante, CPC); la elaboración de planes o programas de acción social dirigidos a personas o grupos vulnerables; la asistencia en el ámbito de actividades comunitarias, tales como elecciones, eventos religiosos, deportivos, sociales y culturales, censos, entre otros eventos sin fines de lucro; la administración de albergues en situación de emergencia.

4 MINISTERIO DE DEFENSA NACIONAL. Ley que crea la Defensa Civil de Chile, 16 de febrero de 1945. Disponible en línea: https://www.leychile.cl/Navegar?idNorma=25744

5 DEFENSA CIVIL. www.defensacivil.cl 
En el caso de la pandemia del Covid-19, la Defensa Civil ha participado de las actividades de refuerzo a la labor de las FF.AA., empezando a marcar una mayor presencia con respecto a ocasiones anteriores. En la Región de Valparaíso, por ejemplo, integrantes de la Defensa Civil, junto con personal de la Onemi, de la organización humanitaria ADRA y de la Gobernación Provincial, ha colaborado con las FF.AA. en presencia de aglomeraciones y grandes filas ${ }^{6}$. En lquique, la Defensa Civil controló el ingreso a un albergue habilitado a través del Comité de Operaciones de Emergencia, con el fin de dar protección a cerca de 700 ciudadanos bolivianos que se encontraban en la frontera sin poder ingresar a su país ${ }^{7}$. Voluntarios de la Sede Local de Peñaflor entregaron una carpa de campaña neumática para que el Hospital de dicha comuna pudiera descongestionar la atención de público en su interior ${ }^{8}$.

Otras actividades realizadas por la Defensa Civil contemplaron el apoyo a distintas sedes de la Caja de Compensación Los Héroes a lo largo del país, la distribución de alimentos a personas vulnerables y en situación de calle, la entrega de kit sanitarios y de cajas con alimentación para las familias más vulnerables, el direccionamiento y traslado de personas, apoyo a campañas de recolección de alimentos, reparto masivo de mascarillas en diferentes calles del centro para cooperar a bajar los posibles contagios, el control sanitario a las personas que ingresan a la comuna por las diferentes rutas a fin de mantener un registro de ellos y minimizar los posibles contagios ${ }^{9}$.

La misión de la Defensa Civil, tal como se encuentra explicitada en su página web, no se contradice con el rumbo que ha tomado el sector de la defensa en Chile en las últimas décadas, configurándose como un actor imprescindible en situaciones que requieren la intervención en desastres y catástrofes, ya sea de origen natural o antrópico. A pesar de las resistencias que existen con respecto a las atribuciones de las FF.AA. en el ámbito de la GRD, que radican en las mismas culturas organizacionales de las instituciones de la defensa, el marco legal establece que las FF.AA. sí cumplen un rol cada vez más importante en dicho ámbito, rol que la Defensa Civil puede y debe poder reforzar en beneficio de la población, cumpliendo su misión a través de sus voluntarios con los que cuenta en cada Sede local.

\subsection{UNA PRESENCIA FRAGMENTADA Y SUPEDITADA AL VOLUNTARISMO}

La Defensa Civil, en la actualidad, cuenta con una presencia fragmentada a lo largo del territorio nacional. Esta entidad, pese a no aparecer referida directamente en el Plan Nacional de Protección Civil (solo se nombra al Ministerio de Defensa), forma parte del trabajo en terreno del MDN en el referido sistema. La Defensa Civil cumple múltiples

6 BIOBíO. Reportan 8 nuevos contagios por covid-19 en la Región de Valparaíso. Disponible en: https:// www.biobiochile.cl/noticias/nacional/region-de-valparaiso/2020/04/23/reportan-8-nuevos-contagiospor-covid-19-en-region-de-valparaiso-total-de-casos-llego-a-429.shtml

7 DEFENSA CIVIL. Labores en Ciudad de Iquique, disponible en línea: https://www.defensacivil.cl/laboresen-ciudad-de-iquique/

8 DEFENSA CIVIL. Defensa Civil apoya a Talagante, disponible en línea: https://www.defensacivil.cl/defensacivil-apoya-a-talagante/

9 DEFENSA CIVIL. Defensa civil en apoyo a la comunidad, disponible en línea: https://www.defensacivil.cl/ defensa-civil-en-apoyo-a-la-comunidad/ 
tareas relacionadas con el apoyo y cooperación a nivel local en la protección civil, difusión de políticas, instrucción a voluntarios en tareas de prevención y en labores de respuesta ante situaciones de emergencia. El accionar de la Defensa Civil se articula en torno a cinco pilares: primeros auxilios, telecomunicaciones, direccionamiento de personas, administración de albergues, y administración de centros de acopio ${ }^{10}$. Estas dos últimas son labores tradicionalmente de responsabilidad de la Defensa Civil en las zonas afectadas por catástrofes.

Sin embargo, la participación de la Defensa Civil en la GRD está, según los consensos políticos actuales, supeditada al voluntarismo. Llama la atención, por ejemplo, que por decreto no está prevista la participación del Director General de la Defensa Civil en el Comité Nacional de Operaciones de Emergencia, que representa la instancia más relevante en caso de que ocurra un desastre de alto impacto, lo que reafirma que el grado de consideración del que dicha institución goza en el ámbito de la GRD es, políticamente, escaso. A niveles inferiores, sobre todo en las comunas, la presencia de la Defensa Civil es bastante más fuerte, lo que refleja el diseño descentralizado del SNPC, del cual la Defensa Civil es parte integrante.

La acción de la Defensa Civil se articula administrativamente desde la Dirección General, que se encuentra en Santiago, hacia las distintas Sedes Locales repartidas alrededor del país. En la actualidad, la Defensa Civil cuenta con Sedes Locales en 43 municipios ${ }^{11}$. Cada Sede local depende de un Jefe de local y de un Jefe de sede. El Jefe de local es un miembro de las FF.AA. y es el encargado de la capacitación de los voluntarios, de dictar las orientaciones necesarias, de realizar las planificaciones y de garantizar la operación y la integridad del patrimonio de la sede. Otras de las funciones del Jefe de local son confeccionar el horario mensual de instrucción y elaborar los informes semestrales de actividades. El Jefe de local, además, representa a la Defensa Civil en los COE comunal y/o regional.

Por su parte, el cargo de los Jefes de sede es ocupado por voluntarios que llevan un tiempo en la organización, y que han ascendido en una jerarquía de voluntarios, determinada por las capacitaciones realizadas. Los Jefes de sede serán los principales colaboradores de los comandantes responsables de cada Sede local (los Jefes de local). Entre las atribuciones del Jefe de sede se encuentran tareas administrativas como llevar los libros de asistencia y labores de asesoría del personal. Este cargo es coadyuvado por un cuerpo de Instructores, que son encargados de la aplicación de las capacitaciones, y por un cuerpo de Asesores Regionales y Comunales. Esta última labor es muy importante, dado que es necesaria una adecuada coordinación con el resto de las organizaciones voluntarias, gubernamentales y locales.

Las municipalidades son las principales interesadas en la cooperación que puede brindarles la Defensa Civil, y por lo mismo son justamente éstas las que más subvencionan a dicho organismo, con montos muy variables de comuna en comuna destinados a las

10 DEFENSA CIVIL DE CHILE. Programa de instrucción y entrenamiento para las sedes locales, 2018, p. 2.

11 DEFENSA CIVIL. Cuenta Pública 2019 completa, disponible en línea:

https://issuu.com/defensacivildechile1/docs/0 cuenta publica 2019 completa.1 
Sedes locales ubicadas en las mismas. Sin embargo, no todas las municipalidades optan por subvencionar a la Defensa Civil: de hecho, las comunas más ricas prefieren tercerizar los servicios que podría realizar la Defensa Civil, optando por contratar empresas privadas en vez de depender del voluntarismo, cuya concurrencia efectiva y consecuente eficiencia es percibida como impredecible. La Defensa Civil funciona principalmente en el nivel municipal, por lo que en caso de desastre o calamidad natural, la primera reacción ocurre a nivel comunal. Si los recursos existentes no son suficientes la municipalidad, a través del Alcalde, solicita ayuda al nivel administrativo superior.

En caso de catástrofe, las Sedes locales deben coordinarse con el Comando Regional, y éste a su vez coordinar con la Sede Central. La Defensa Civil participa de los Comité de Operaciones de Emergencia (COE). Cabe destacar que, en caso de emergencia, las Sedes locales funcionan en estrecha coordinación con las oficinas regionales de la ONEMI. En el caso de los aluviones en Copiapó, por ejemplo, la coordinación de la respuesta a la emergencia ocurrió a través del Comandante local, que en coordinación con la ONEMI regional, y tras la organización de Comité de Emergencia, organizó las actividades de la Defensa Civil -habilitación de centros de acopio, albergues, etc...- según las necesidades que presentaba la situación.

\subsection{ESCASOS RECURSOS ECONÓMICOS Y HUMANOS}

Finalmente, a la base de la institucionalidad de la Defensa Civil está el cuerpo de voluntarios, quienes pueden ser asignados como un salvoconducto en caso de ser llamados al Servicio Militar Obligatorio, ser voluntarios locales que hayan cumplido la mayoría de edad, o que tengan la autorización de sus padres en caso de ser menores de dieciocho años. El gran desafío que presenta la coordinación entre la ONEMI a nivel regional y la Defensa Civil a nivel municipal es justamente la incertidumbre acerca de la cantidad de voluntarios con los que esta última puede contar: uno de los mayores problemas de la Defensa Civil es que, hoy en día, faltan incentivos para formar parte de la organización, principalmente porque las preocupaciones de la gran mayoría de los jóvenes están muy lejanas de lo que es la misión de esta institución.

Si bien la Defensa Civil tiene como base el trabajo de voluntarios, esta organización también cuenta con personal por medio del Servicio Militar Obligatorio (SMO). En 2005 el entonces el ministro de Defensa Nacional, Jaime Ravinet, firmó la Ley № 20.045, la cual buscaba modernizar el Servicio Militar Obligatorio. Esta ley instauró el mecanismo de sorteo, la inscripción automática en los registros militares, entre otras novedades. Entre las reformas introducidas en 2005 a la ley anterior, que se remonta al año 1978, se encuentran las modificaciones el Artículo № 15. Estas establecieron que los varones disponibles "podrán ser destinados a servir en la Defensa Civil de Chile hasta por un tiempo equivalente al de la conscripción"12. De esta forma se estableció un salvo conducto para que los llamados al servicio militar puedan participar de la Defensa Civil.

Además de existir la necesidad de incentivar una cultura y un trabajo orientado a la

12 MINISTERIO DE DEFENSA NACIONAL. Ley 20.045 que moderniza el Servicio Militar Obligatorio. Disponible en línea en : https://www.leychile.cl/Navegar?idNorma=241847 
prevención de riesgos futuros en las propias comunidades, aún falta una disposición legal que establezca la obligatoriedad de contar con departamentos municipales dedicados exclusivamente a la GRD. El proyecto de ley que crea la Agencia de Protección Civil establece que cada municipio tendrá que contar con una Oficina de emergencia, lo que permitiría coordinar, entre todos los actores locales, incluida la Defensa Civil, los esfuerzos de respuesta ante emergencias y evitar situaciones como la ocurrida en ocasión de un desborde de río en Tocopilla y de los incendios en la Región del Biobío, en las cuales la Dirección General de la Defensa Civil tuvo que movilizar recursos desde Santiago porque en dichas zonas no se contaba con una cantidad de recursos humanos y materiales adecuada.

Pese a la amplia trayectoria histórica y a la cobertura territorial que alcanzó en el pasado, en la actualidad la Defensa Civil de Chile se encuentra aquejada por una serie de problemas. El primero de ellos es que el presupuesto es insuficiente para garantizar su buen funcionamiento. El año 2019 la Defensa Civil contó con un presupuesto de $\$ 400.181 .959$ (CLP), siendo \$107.367.959 adquiridos por concepto de subvenciones municipales ${ }^{13}$. Solo 29 municipios, es decir el 63\% de las comunas que cuentan con Sedes Locales, otorgaron recursos para solventar a la Defensa $\mathrm{Civi}^{14}$. La asignación presupuestaria otorgada por el Ministerio de Defensa corresponde a $\$ 292.814 .000$. A pesar de haber habido un aumento significativo en el presupuesto con respecto a años anteriores, con los recursos actuales no es posible satisfacer las demandas reales de las sedes locales, dado que el $65 \%$, es decir $\$ 202.953 .000$, de esta asignación se gasta en concepto de Personal, y los $\$ 87.741 .777$ restantes se gastan por concepto de Bienes y Servicios a beneficio de la sede de Santiago ${ }^{15}$.

De esta primera problemática se desprende la segunda complicación que experimenta la Defensa Civil, es decir la falta de infraestructura y equipamiento. En los últimos 15-20 años, las Sedes locales han disminuido prácticamente a la mitad; además, algunas de ellas se encuentran en pésimas condiciones. Tampoco existe un monto de recursos adecuado para adquirir el equipamiento necesario, ni para contratar personal remunerado. Los voluntarios reciben, en función de las capacidades de la sede local, capacitación y equipamiento, pero no cuentan ni con seguro contra accidentes ni con fuero laboral, en caso de querer prestar ayuda en alguna emergencia. El voluntariado de un miembro de la Defensa Civil, por lo tanto, se reduce a su asistencia a la Sede local los días sábado, y a la participación de actividades de formación, capacitación y preparación, y de apoyo a la comunidad dentro de sus posibilidades.

La ausencia de Jefes de Sedes locales remunerados es otro problema serio, que perjudica el mantenimiento de la integridad de las sedes y el desarrollo ordenado de sus actividades. Al ser voluntario y no dependiente de la administración pública, dicha figura no carga con ninguna responsabilidad administrativa hacia los bienes de la sede ni hacia las personas que participan de sus actividades. Esto se potencia por el tercer factor crítico que aqueja a la institución, la falta de una legislación adecuada. La normativa vigente, la Ley № 8.059 y su reglamento complementario datan del año 1945, por tanto, se encuentran totalmente descontextualizados de las exigencias del presente. A pesar de

13 DEFENSA CIVIL DE CHILE. Cuenta pública 2019, p. 97.

14 Ibíd. p. 99.

15 Ibíd. 
que ha habido tres intentos consecutivos de presentar un proyecto de ley de Protección Civil que modernice y fortalezca la Defensa Civil de Chile, dichos proyectos de ley no han sido objeto de debate en el Congreso. Esto deja al organismo en un limbo legal que reduce significativamente su potencial, en términos del aporte que podría realizar al Sistema Nacional de Protección Civil, maximizando la eficiencia del sistema a través de su institucionalización.

\section{EL CONTEXTO: EL SISTEMA NACIONAL DE PROTECCIÓN CIVIL}

Antes de entrar al tema de la participación de las FF.AA. en el SNPC, vale la pena detenerse en el funcionamiento y marco legal que sustenta dicho sistema. Con el objetivo de proteger a las personas, sus bienes y al medio ambiente, el SNPC organiza un complejo sistema de interrelación y cooperación entre organismos públicos (ministerios y servicios públicos) y privados (empresas nacionales y extranjeras), ONG (nacionales e internacionales) y actores de la sociedad civil organizada (comunidad, voluntarios y juntas de vecinos). Entre los organismos públicos que cumplen un rol de mayor importancia se encuentran el Ministerio de Relaciones Exteriores, el Ministerio de Interior y Seguridad Pública y el Ministerio de Defensa. El primero se encarga de canalizar la ayuda humanitaria; el segundo, a través de la ONEMI, se preocupa de coordinar los esfuerzos de prevención y entrenamiento para la entrada en acción de diferentes actores en caso de emergencia; el tercero interviene toda vez que las FF.AA. son llamadas a participar en distintos niveles e instancias que articulan el SNPC.

Como se ha mencionado, el SNPC se sustenta en la Constitución Política de la República de Chile, Artículo $1^{\circ}$, inciso $5^{\circ}$. Con la finalidad de cumplir con dicha garantía constitucional, se han desarrollado progresivamente una serie de normativas que guardan relación con los deberes del Estado en la GRD. El marco legal en el que se inserta el SNPC tiene sus raíces en disposiciones legales que se remontan a las primeras décadas del siglo veinte. Entre ellas destaca el Decreto con Fuerza de Ley $N^{\circ} 7.912$ de 1927, del Ministerio del Interior, que organiza las Secretarías de Estado, y que en su artículo $3^{\circ}$ estableció que al Ministerio del Interior le corresponde todo lo relativo al mantenimiento de la seguridad, tranquilidad y orden público. Sucesivamente, el Decreto con Fuerza de Ley Nº 22 de 1959, que fija el Texto de la Ley Orgánica del Servicio de Gobierno Interior de la República, dispuso que los intendentes y gobernadores están facultados para requerir, de los jefes de servicios sujetos a su fiscalización, la atención inmediata y los fondos extraordinarios necesarios para enfrentar una emergencia.

El hito más importante en la evolución del SNPC fue, sin lugar a duda, la promulgación del Decreto de Ley Nº 369 de 1974, que crea la Oficina Nacional de Emergencia (en adelante, ONEMI). Esta última es un servicio público dependiente del Ministerio del Interior, y sus atribuciones se relacionan con la planificación, coordinación y ejecución de toda actividad destinada a prevenir o solucionar situaciones problemáticas derivadas de sismos o catástrofes. También le corresponde planificar y coordinar el empleo de los recursos humanos y materiales de las entidades y servicios públicos y privados que tengan la capacidad de cooperar en alguna arista de la respuesta y reconstrucción post catástrofe o calamidad, con la finalidad de prevenir y reducir los daños derivados de tales eventos, pudiendo además requerir de esos servicios toda la información necesaria 
para el cumplimiento de sus atribuciones. Por medio del Decreto $\mathrm{N}^{\circ} 737$, el Presidente de la República conformó una comisión que propusiera un Plan Nacional de Emergencia para enfrentar las emergencias producto de terremotos u otras calamidades, el cual fue promulgado el año 1977. El Decreto Supremo N 509 de 1983, del Ministerio del Interior, que establece el reglamento para el funcionamiento de la ONEMI, en cambio, contiene las disposiciones necesarias para operacionalizar las atribuciones de dicha agencia. La normativa mencionada estableció la orgánica de la organización y las atribuciones de cada uno de sus departamentos.

Para los fines de este trabajo, resulta interesante destacar la existencia, en seno a la ONEMI, del Departamento de Protección Civil. De acuerdo con el artículo 18 de la normativa mencionada, este departamento tiene atribuciones que varían en situación de normalidad o emergencia. En tiempos de normalidad, dicho departamento se preocupa de planificar, elaborar estudios, proponer programas y normas, y controlar su ejecución; asesorar al Director General en la planificación de emergencia; analizar variables implicadas en la ocurrencia de catástrofes o calamidades para establecer sus causas; recomendar las correspondientes medidas preventivas o de mitigación; desarrollar programas de capacitación en prevención de desastres destinados al perfeccionamiento del personal de la ONEMI y, finalmente, la preparación de expertos en Protección Civil. Durante situaciones de emergencia, en cambio, al Departamento de Protección Civil le corresponde apoyar con todo su personal las operaciones de emergencia en la sede de la ONEMI o en la zona de catástrofe, para llevar el control del estado de la situación, evaluar los daños y llevar su registro estadístico.

Posteriormente, la Ley Nº 19.175 de 1992, Orgánica Constitucional sobre Gobierno y Administración Regional profundiza el enfoque descentralizado que caracteriza el marco legal del SNPC desde sus inicios. Dicha normativa dispone que es responsabilidad de los gobiernos regionales, y de los respectivos intendentes y gobernadores, adoptar las medidas necesarias para enfrentar situaciones de emergencia o catástrofe y desarrollar programas de prevención y protección ante las mismas. Si bien la tendencia descentralizadora de las responsabilidades había estado instalada desde principios de siglo en la visión política de cómo los desastres y catástrofes debían ser enfrentados, es solo a partir de la creación de la ONEMI que se comienza a pensar en un enfoque coordinado e integrado desde el centro, pero caracterizado por la presencia de oficinas de la agencia en cada una de las regiones del país y por responsabilidades descentralizadas hacia los niveles regional, provincial y comunal. Dicho enfoque coordinado y descentralizado se concreta a través del Decreto Supremo N 156 de 2002, que aprueba el Plan Nacional de Protección Civil (en adelante, PNPC), que sin lugar a dudas constituye el siguiente hito más importante que marcó la evolución del SNPC.

EI PNPC derogó el Plan Nacional de Emergencia de 1977 y constituye un instrumento indicativo para la GRD en Chile, concebida como una realidad dinámica y controlable, que es indispensable para continuar el proceso de desarrollo sostenible del país, y que requiere del fortalecimiento de las condiciones de seguridad necesarias para brindarle a la población una mejor calidad de vida. EI PNPC tiene como objetivo general el de dotar al país de una planificación multisectorial en materia de Protección Civil, que predisponga un marco de acción permanente para la prevención de y la intervención en desastres 
o emergencias. El énfasis del PNPC recae en las tareas de prevención, mitigación y preparación ante la potencial ocurrencia de desastres o catástrofes, en una lógica de acción que apunta a disminuir los recursos humanos, materiales y económicos a emplear en la fase de respuesta ${ }^{16}$.

El enfoque integral a la GRD propuesto por el PNPC prevé una coordinación participativa, interinstitucional e intersectorial, que involucra tanto organismos públicos como privados. Dicha coordinación debe estar enfocada a la identificación de las amenazas, riesgos y vulnerabilidades específicas de una determinada zona jurisdiccional (comuna, provincia, región), así como de los recursos a disposición y de la planificación de la respuesta ante la ocurrencia de un desastre. En otras palabras, el PNPC adopta un enfoque integral pero descentralizado, que permite que cada zona jurisdiccional identifique los riesgos y amenazas a las que está expuesta, así como los recursos a disposición y la mejor manera de enfrentarlas.

EI SNPC aludido anteriormente se basa en una red de Comités de Protección Civil, que se constituyen a nivel nacional, regional, provincial y comunal, y que son presididos respectivamente por el ministro del Interior, los intendentes, los gobernadores y los alcaldes. Los CPC reúnen a los representantes de organismos públicos y privados, que por sus características y misión tienen la capacidad de realizar un aporte, en términos de recursos humanos, materiales y técnicos, al esfuerzo coordinado de prevención, preparación e implementación de planes previos a la ocurrencia de desastres. La autoridad política que preside a cada uno de estos Comités tiene la atribución de designar al Director de Protección Civil y Emergencia, quien asesora a dicha autoridad en las distintas fases del ciclo del riesgo.

Los CPC, que constituyen órganos de trabajo permanente en tiempos de normalidad, se constituyen en Comités de Operaciones de Emergencia cuando ocurre un evento de carácter desastroso o catastrófico. Las atribuciones de los COE tienen que ver con la respuesta y rehabilitación ante la ocurrencia de un desastre en la respectiva zona jurisdiccional. De acuerdo con el PNPC, debe existir un COE en cada zona jurisdiccional, cuyo lugar físico y equipamiento debe ser facilitado, en el caso del COE Nacional por la ONEMI, y en el caso de los COE de los niveles políticos y administrativos inferiores por las autoridades que los presiden. El estado actual de la red de CPC, sin embargo, no es alentador: solo un número menor de comunas, de las casi 350 comunas de Chile, cuentan con CPC habilitados y funcionando, mientras que la gran mayoría de las comunas del país no han implementado lo dispuesto por el PNPC, lo que choca inevitablemente con otra normativa anterior, la Ley $N^{\circ} 18.695$ de 2006, sobre la Orgánica Constitucional de Municipalidades, en la cual se establece que la prevención de riesgos y la prestación de auxilio en situaciones de emergencia es responsabilidad de los municipios ${ }^{17}$.

16 ONEMI. Plan Nacional, Instrumento Indicativo para la Gestión Integral. Decreto №156 del 12 de marzo de 2002. Disponible en línea: http://www.onemi.cl/wp-content/themes/onemi-bootstrap-master/library/ doc/plan_nacional_0_0.pdf

17 No todos los municipios del país están dotados de departamentos de emergencia, cuyas funciones son desempeñadas por los departamentos de seguridad ciudadana, que no siempre están preparados para asumir atribuciones en el ámbito de la GRD. 
La evolución del SNPC, caracterizada por una marcada tendencia descentralizadora desde sus inicios, no ha impedido el fortalecimiento de instancias centralizadas a nivel nacional, que se conforman en las emergencias de mayor envergadura. Uno de los hitos que contribuyó al fortalecimiento de la coordinación centralizada de los esfuerzos del Estado en la GRD fue la creación del Comité Nacional de Operaciones de Emergencia (en adelante, COE Nacional). El Decreto Supremo No38 de 2011, que determina la constitución de dicha instancia, indica que esta última debe constituirse cuando se registren emergencias, desastres o catástrofes que provoquen daños considerables a las personas y/o a sus bienes, que afecten a todo el país, a una o más regiones, o si el siniestro provoca un alto impacto en la población en virtud de su magnitud. Los miembros integrantes del COE son los ministros que presiden las carteras de Interior y Seguridad Pública, este último acompañado por el subsecretario del Interior; Defensa Nacional; Energía; Transporte y Telecomunicaciones; Salud; Obras Públicas; el Jefe del Estado Mayor Conjunto y el Director Nacional de la ONEMI.

Ante la ocurrencia de un desastre o catástrofe de carácter nacional, en los términos antes indicados, el COE Nacional es convocado por el Director de la ONEMI y presidido por el ministro del Interior. El ministro del Interior puede convocar al COE Nacional a otras autoridades, así como a representantes de instituciones públicas o privadas, de acuerdo a la naturaleza del desastre o catástrofe. Tal facultad puede ser delegada en el Director Nacional de la ONEMI. Ante la ocurrencia de un desastre o catástrofe de carácter regional, y no obstante que se disponga la constitución del COE Nacional, según lo indicado anteriormente, se constituye un Comité Regional de Operaciones de Emergencia (en adelante, COE Regional), el que es presidido por el Intendente Regional. En lo que concierne a aquellos desastres o catástrofes que afecten a una determinada provincia o comuna, se constituirán Comités Provinciales o Comunales de Operaciones de Emergencia (en adelante COE Provinciales o Comunales), según corresponda, sin necesidad de constituir el COE Nacional ${ }^{18}$.

Otro hito importante en el desarrollo del SNPC es constituido por la creación de la Academia de Protección Civil de la ONEMI, mediante la Resolución Exenta N² 282 de 2009. Esta tiene por visión "Constituirse en un referente nacional e internacional en los procesos de formación y capacitación en Gestión Integral del Riesgo del Sistema Nacional de Protección Civil", y por misión "Coordinar, desarrollar y proveer programas de formación, capacitación y entrenamiento a todos los segmentos del Sistema Nacional de Protección Civil, según su rol específico en la gestión integral del riesgo, de manera de contribuir a la reducción de vulnerabilidades y al desarrollo de una cultura de la prevención"19. Desde entonces este organismo ha coordinado e implementado diversos programas de formación dirigidos a los integrantes del Sistema Nacional de Protección Civil, como por ejemplo el diplomado "La Seguridad y Defensa en la Gestión del Riesgo de Desastres", dictado en conjunto con la Academia Nacional de Estudios Políticos y Estratégicos, el cual busca formar a profesionales para el trabajo coordinado entre los distintos organismos

18 MINISTERIO DEL INTERIOR Y SEGURIDAD PÚBLICA. Decreto $\mathrm{N}^{\circ} 38$ del 18 de enero de 2018, que modifica el Decreto $N^{\circ} 156$ de 2002 y determina constitución de los Comités de Operaciones de Emergencia. Disponible en línea: http://www.amuch.cl/wp-content/uploads/2017/03/Comites-de-Operaciones-deEmergencia.pdf

19 ONEMI. Bases Generales para la Formación y Capacitación en Gestión Integral del Riesgo, p. 16. 
públicos y privados que confluyen en el SNPC.

Tras el devastador terremoto de 2010 se elaboró un proyecto de ley que crea un nuevo Sistema de Emergencia y Protección Civil, y reemplaza la ONEMI por la Agencia de Emergencia y Protección Civil ${ }^{20}$. Dicho proyecto fue firmado durante el primer mandato del presidente Sebastián Piñera, en medio de críticas a la reacción del primer gobierno de Michelle Bachelet al mega terremoto y tsunami del 27-F, y pasó al segundo trámite constitucional el 13 de marzo de 2013, con urgencia calificada de "suma". Desde aquella fecha este proyecto de ley fue discutido y aprobado por la Comisión de Gobierno, Descentralización y Regionalización, y enviado a trámite por la Sala del Senado ante las Comisiones de Defensa Nacional y de Hacienda. A pesar de los sucesivos anuncios políticos sobre la continuidad del proyecto, el mismo sigue en el segundo trámite constitucional con urgencia calificada de "simple"21.

El año 2016, por medio del Decreto Supremo $N^{\circ} 1.512$, la entonces presidenta de la República Michelle Bachelet aprobó la Plataforma Nacional de Reducción del Riesgo de Desastres (en adelante, PNRRD), constituyéndose ésta como el primer instrumento nacional en materias de RRD. Dicha plataforma busca contribuir al avance en la planificación segura y sustentable del desarrollo, incorporando de manera efectiva las políticas sectoriales de planificación del territorio, reducción de la pobreza, adaptación al cambio climático, cultura del auto cuidado, protección financiera, fortalecimiento de capacidades, investigación y análisis del riesgo y atención integral a poblaciones vulnerables ${ }^{22}$. En el intertanto, también fue aprobada la llamada Política Nacional para la Gestión del Riesgo de Desastres (PNGRD), que surgió como una respuesta a la escasa preparación del país ante el terremoto y tsunami del 27 de febrero de 2010, en el marco de la evaluación de los avances del Marco de Acción de Hyogo (MAH). Dicha misión destacó la importancia de renovar los mecanismos de coordinación intersectorial e interinstitucional entre los actores involucrados en materias de Reducción del Riesgo de Desastres.

El Plan Estratégico Nacional para la Gestión del Riesgo de Desastres 20152018 (en adelante, PENGRD), finalmente, es el instrumento que define los objetivos estratégicos, programas, acciones, plazos y responsables con el objetivo de poner en práctica lo establecido en la PNGRD; tanto este como el PENGRD tienen la finalidad de fortalecer los aspectos proactivos de la GRD, y de crear comunidades resilientes en el marco del paradigma de RRD, centrado más en la prevención que en la respuesta. Para cada una de las cinco áreas a fortalecer de acuerdo con el Marco de Acción de Hyogo, el PENGRD estableció objetivos estratégicos en base de una metodología que contempló la participación de una multiplicidad de actores que desempeñan distintos roles en la GRD. La Defensa Civil participó de las reuniones que tuvieron como objetivo fortalecer la preparación ante los desastres para lograr una respuesta eficaz.

20 EMOL. "Con críticas a Bachelet ejecutivo firma proyecto de agencia nacional de protección civil". Disponible en línea: https://www.emol.com/noticias/nacional/2011/02/22/466119/con-criticas-abachelet-ejecutivo-firma-proyecto-de-agencia-nacional-de-proteccion-civil.html

21 CÁMARA DE DIPUTADOS DE CHILE. “Proyectos de ley en tramitación”. Disponible en línea: https://www. camara.cl/pley/pley_detalle.aspx?prmID=7940

22 ONEMI. Política Nacional para la Gestión del Riesgo de Desastres, p. 11. 
Merece la pena detenerse en lo que plantea el proyecto de ley que crea la Agencia Nacional de Emergencia, o "nueva ONEMI". Cuando la iniciativa fue ingresada al Congreso por primera vez, se observaba que, en Chile, la estructura institucional para la emergencia se había concentrado solo en el manejo de la respuesta. Como menciona el mismo proyecto, la ONEMI "fue inicialmente creada como una bodega de almacenamiento y distribución de materiales y alimentos. Con el tiempo, fue adquiriendo competencias de orden técnico, por ejemplo en materia de medición del riesgo y de comunicación mediante sistemas de alerta temprana". Desde 2010, con apoyo del Banco Interamericano de Desarrollo (BID), ONEMI realizó estudios orientados a formular un diagnóstico institucional y a definir las competencias y funciones que la nueva Agencia debiese desempeñar, para operar más acorde con los desafíos que plantea la prevención y aminoración de los daños de desastres o catástrofes.

La iniciativa mencionada estaba basada en los principios de prevención, subsidiariedad e intersectorialidad, con el propósito de robustecer y modernizar la institucionalidad actual. Para fortalecer el ámbito de la prevención, el proyecto inicial incorporó tres grandes innovaciones: primero, la creación de la Agencia Nacional de Protección Civil, con una serie de competencias en materia de prevención y reducción de riesgos; segundo, la formación del Consejo Nacional de Protección Civil como instancia encargada de la elaboración de una estrategia nacional de RRD; tercero, el establecimiento del Fondo Nacional para la Protección Civil, que garantizaría el financiamiento a diferentes iniciativas sectoriales orientadas a prevenir y reducir vulnerabilidades. Para materializar el principio de subsidiariedad el proyecto reconocía el rol central que deben cumplir los municipios en la GRD, y creaba Comités Regionales encargados de elaborar Estrategias Regionales de Protección Civil. Para incrementar la intersectorialidad, en cambio, el proyecto preveía un mayor involucramiento de las FF.AA. en la fase de respuesta, y el establecimiento de las capacidades de la defensa al servicio del Sistema Nacional de Emergencia para desempeñar tareas de naturaleza humanitaria.

La Agencia Nacional de Protección Civil constituiría un servicio público descentralizado, con personalidad jurídica y patrimonio propio, que tendría la atribución de coordinar y ejecutar las acciones de prevención de emergencias y protección civil, y asesorar a las autoridades en las labores de planificación y coordinación de emergencias. Tal como en el caso de la ONEMI, que cuenta con Oficinas Regionales, además de una Agencia Central existirían Direcciones Regionales en cada región del país. Las funciones de la Agencia deben desarrollar, coordinar y ejecutar todas las acciones orientadas a la reducción de los riesgos, al mejoramiento de la capacitación en la reacción ante una catástrofe, y a la coordinación el trabajo conjunto con otras instituciones, nacionales o locales en el ámbito de la RRD. Algunos de los proyectos y programas a cargo de la Agencia serían: programas de capacitación y entrenamiento en protección civil, campañas de difusión, estudios de riesgo, protocolos de alerta temprana, simulacros de emergencia y mapas de riesgo, entre otros.

Con la finalidad de incrementar la intersectorialidad, la iniciativa proponía que el Ministerio de Defensa Nacional, a través del Estado Mayor Conjunto, fuera el responsable de obtener y sistematizar la información respecto de los recursos y capacidades de las instituciones de las Fuerzas Armadas, y de elaborar los planes y protocolos de operación 
para situaciones de preparación, atención y reacción frente a una emergencia. El Comité de Operaciones de Emergencia sería el organismo que requeriría el empleo de las Fuerzas Armadas en funciones de apoyo a la emergencia a través del Ministerio de Defensa Nacional, mientras que los medios de apoyo serían coordinados por el Jefe de Estado Mayor Conjunto (JEMCO). De acuerdo con el proyecto inicial, el EMCO debía asesorar el MDN en asuntos relacionados con el apoyo logístico, el reporte de daños, el empleo de las capacidades militares existentes en la zona afectada y el estudio de alternativas de intervención, y además debía establecer un Cuartel General de Emergencia en la zona afectada.

El MDN, por su parte, designaría a Autoridades Militares de Enlace, quienes dirigirían las fuerzas militares existentes en la zona afectada por la emergencia, recopilarían y centralizarían toda la información relacionada con la emergencia en dicha zona informando y asesorando durante la emergencia al COE y al MDN. Las Autoridades Militares reaccionarían en apoyo de la emergencia coordinando los medios de las Fuerzas Armadas a su disposición, en conformidad a los planes, protocolos y acuerdos establecidos, pudiendo solicitar al EMCO recursos adicionales. Las unidades de las Fuerzas Armadas y Carabineros de Chile que tuvieran bajo su dependencia medios de la Defensa Civil de Chile dentro de una zona afectada por una emergencia, procederían a movilizarlas y desplegarlas, asignándoles un mando y poniéndolas a disposición del COE.

Con la finalidad de fortalecer la prevención de emergencias, el proyecto en cuestión también propuso la creación del Consejo Nacional de Protección Civil y de los Comités de Protección Civil. El Consejo funcionaría como organismo asesor del Ministerio del Interior en la elaboración de una Estrategia Nacional de Protección Civil, mientras los Comités de Protección Civil (CPC) funcionarían como organismos permanentes de asesoría a las intendencias regionales en temas relacionados con la GRD. Los CPC tendrían la tarea de desarrollar Estrategias Regionales de Protección Civil, mientras cada Administración del Estado tendría que desarrollar Planes Sectoriales de Protección Civil. Otro apartado fundamental del proyecto de ley se relacionaba con el Sistema Nacional de Alerta Temprana, cuya dirección y funcionamiento estaría a cargo de la Agencia.

Dado que el proyecto mencionado se encuentra aún en el segundo trámite constitucional, el documento que rige el actuar de las instituciones frente a la amenaza constituida por la ocurrencia de desastres o catástrofes sigue siendo el PNPC. Si bien el PNPC y el SNPC se articulan bajo el paraguas del Ministerio del Interior y Seguridad Pública, las tareas vinculadas con la Protección Civil no son cumplidas exclusivamente por dicho ministerio por distintas razones; la primera es de carácter histórico, ya que los primeros pasos que la Defensa Civil dio, como organismo dedicado a la protección de la población, se dieron en el ámbito de la defensa. La segunda razón es de índole práctico, ya que e técnicos y materiales para implementar una tarea titánica como lo es la protección civil en un país altamente susceptible de ser azotado en forma recurrente por desastres y catástrofes. En la siguiente sección se analizará el marco legal y funcionamiento de la participación de las FF.AA. en el ámbito de la GRD. 


\section{LA PARTICIPACIÓN DE LAS FF.AA. EN LA GESTIÓN DEL RIESGO DE DESASTRES EN EL MUNDO}

Las Fuerzas Armadas, como actores clave dentro de toda organización estatal, se vuelven aliados trascendentales cuando se trata de preservar la seguridad y bienestar de la ciudadanía frente a la amenaza de una emergencia o catástrofe. El caso de la pandemia protagonizada por el virus COVID-19 no es la excepción. Las FF.AA. cuentan con recursos humanos, materiales y técnicos que, si bien fueron concebidos para desempeñar tareas de defensa y disuasión frente a enemigos externos, han asumido progresivamente un carácter polivalente. Dicho carácter no es nuevo, porque en el pasado la defensa no solo combatía guerras, sino que además intervenía en situaciones de desastre o catástrofe. No solo por su dotación de medios humanos y materiales, sino también por su preparación, estructura jerarquizada, disciplina, y sobre todo por su alto grado de disponibilidad, las FF.AA. se encuentran preparadas para intervenir, en todo momento, para reforzar los esfuerzos de otras instituciones ${ }^{23}$.

En definitiva, las Fuerzas Armadas constituyen un aliado clave cuando existe la necesidad de amortiguar los efectos de catástrofes o de infundir confianza en la población. Sin embargo, y sobre todo en Chile, la intervención de las FF.AA. se vuelve aún más crucial que en otros países debido a la alta incidencia de catástrofes naturales, y quizás es aún más compleja que en otros contextos en virtud de las particularidades del sector de la defensa, de sus relaciones aún algo tensas con el mundo civil a raíz de la historia reciente, del peso que han mantenido las instituciones de las FF.AA. durante y después de la transición a la democracia, y de las relaciones de poder que existen en su interior. La situación se complica si se toma en cuenta la cultura organizacional de dichas instituciones, que tienden a tener una visión ambivalente de las tareas que las FF.AA. asumen en la GRD: por un lado, dichas tareas no son consideradas parte de la misión de las FF.AA. pero, por el otro, se estima que es principalmente ante estas situaciones que las instituciones tienen la oportunidad para poner a prueba sus capacidades.

La compenetración civil-militar en el manejo de catástrofes es ampliamente observada en distintos países del mundo. Según la Oficina de la ONU para la Coordinación de Asuntos Humanitarios (OCHA), los militares pueden contribuir valiosamente a la acción humanitaria a través de su capacidad para movilizar y desplegar rápidamente los recursos y conocimientos técnicos en respuesta a requisitos específicamente identificados. Además, la coordinación humanitaria civil-militar, si es eficaz, constante y es concebida y planificada estratégicamente como una responsabilidad compartida, puede ser crucial para salvaguardar los principios y el espacio humanitario ${ }^{24}$.

Un país que tiene una vasta experiencia en manejo de desastres es Estados Unidos. La oficina encargada de la GRD es la Agencia Federal para la Gestión de Emergencias (FEMA, por sus siglas en inglés). Esta agencia se encarga de las respuestas antes desastres naturales como huracanes, terremotos, inundaciones y otras emergencias

23 SIERRA Méndez, José. "Protección civil y Fuerzas Armadas", Instituto Español de Estudios Estratégicos, Cuaderno de Trabajo N¹65, 2013. pp. 69-98.

24 OCHA. Mensaje: Coordinación civil-militar, 2012 Ginebra, p. 2. Disponible en: https://www.unocha.org/ sites/unocha/files/dms/Documents/OCHA\%20on\%20Message_Civ_Mil_vSP.pdf 
que afectan el territorio estadounidense. FEMA depende desde el 2011 del Departamento de Seguridad Nacional de Estados Unidos. Esta entidad opera en aquellos momentos en los cuales las autoridades locales y estatales se ven sobrepasadas. Su misión es "guiar a los Estados Unidos para que se preparen, prevengan, respondan y se recuperen de los desastres con la visión de una nación preparada"25. Esta agencia tiene sus orígenes en 1979, cuando el presidente Jimmy Carter firmó la orden ejecutiva que creó FEMA. En este organismo se unificaron diversas agencias encargadas de la GDR, asumiendo múltiples competencias, entre las que se encuentra la responsabilidad de la defensa civil por medio de la creación de la Agencia de Preparación Civil de Defensa del Departamento de Defensa ${ }^{26}$. En 2018 FEMA contaba con un presupuesto de 18 mil millones $^{27} y$ con más de 9.000 empleados $^{28}$.

Chile cuenta con una larga historia de cooperación con EE.UU. en materia de GDR, siendo este una referencia muy utilizada por nuestro país. El año 2016, el subadministrador de FEMA, Timothy Manning, y el Director Nacional de la ONEMI, Ricardo Toro, firmaron un Memorándum de Entendimiento para fortalecer la gestión de la respuesta en casos de emergencias y catástrofes. Este tiene por finalidad mejorar la prevención, preparación, y respuesta a desastres mediante el intercambio de conocimientos e información, capacitación, educación, y tecnologías. Uno de los objetivos principales de esta iniciativa es la entrega de apoyo técnico para la implementación de la metodología C.E.R.T (Community Emergency Response Teams, o equipos comunitarios de respuesta ante emergencias) y el intercambio de profesionales en la Academia Nacional de Protección Civil de la ONEMI ${ }^{29}$.

En la región latinoamericana abundan los casos de cooperación militar-civil en la GRD. Un caso emblemático es la Defensa Civil colombiana, una institución social y humanitaria de rescate y socorro que se encuentra al alero del Ministerio de Defensa. Esta organización está afiliada con el Sistema Nacional de Prevención y Atención a Desastres (SNPAD). Dicho sistema opera tanto en las labores de prevención de desastre y calamidades, promoviendo el entrenamiento y capacitación, como también en las labores en terreno post desastre, como búsqueda, rescate y primeros auxilios. La Defensa Civil colombiana tiene sus orígenes con la creación, en 1948, del Socorro Nacional, el cual se conformó como un grupo auxiliar del Ejército que prestaba asistencia pública atendiendo a la población civil en casos de desastres.

En 1967, por medio del Decreto Legislativo No. 606, se instituyó la Dirección Nacional de la Defensa Civil bajo la autoridad de la Presidencia de la República de Colombia. La Dirección estaba conformada por dos niveles: el oficial, constituido por los empleados

25 FEMA. History. Disponible en línea: https://www.fema.gov/about-agency

26 FEMA. Executive Order 12127. Disponible en línea: https://www.fema.gov/about-agency

27 FEMA. Budget overview, 2018. https://www.dhs.gov/sites/default/files/publications/FEMA\%20FY18\%20 Budget.pdf

28 THE WASHINGTON POST. Disponible en línea: https://www.washingtonpost.com/news/wonk/wp/2012/11/03/fema-has-9106-disaster-assistanceemployees-only-770-get-federal-health-insurance/?utm_term=.e2a5830e4d01

29 US EMBASSY CHILE. Onemi y Agencia federal de Emergencias de los EE.UU. firman acuerdo. Disponible en línea: https://cl.usembassy.gov/es/onemi-y-agencia-federal-de-emergencias-de-los-ee-uu-firmanacuerdo/ 
públicos adscritos a la actual Dirección General y sus dependencias, y el privado constituido por los voluntarios que se organizan en Juntas de Defensa Civil. En 1971 mediante el Decreto $\mathrm{N}^{\circ} 2341$ esta entidad pasó a establecerse como una organización pública con personalidad jurídica, autonomía administrativa y patrimonio independiente, pero adscrito al Ministerio de Defensa Nacional. Desde entonces la entidad ha formado parte integral de la SNPAD, desplegándose periódicamente en todo tipo de desastres naturales y de naturaleza antrópica. Un elemento interesante de esta entidad es que forma parte del Grupo Social y Empresarial de la Defensa (GSED), un conglomerado compuesto por 18 empresas cuyo propósito es apoyar la misión de las Fuerzas Armadas y de la Policía Nacional, y velar por el bienestar y la seguridad social de sus miembros. Esto la convierte en la asociación social y humanitaria más grande del sector público colombiano ${ }^{30}$.

Al otro lado del Atlántico, Francia destaca como un modelo de gestión de catástrofes con un arraigo muy fuerte en la Defensa Civil. La primera iniciativa fueron las llamadas Formaciones Militares de Seguridad Civil (FORMISC), que fueron implementadas por el general De Gaulle tras el desastre causado por el derrumbe de una represa sobre la ciudad de Frejus, que causó la muerte de 423 personas el invierno de 1959. Dada la falta de recursos humanos que pudiesen intervenir en este tipo de situaciones, el general decidió emplear soldados para realizar misiones de protección civil. En 1964 se creó la primera Unidad de Seguridad Civil, y en 1988 se instituyó por decreto el Mando de las Formaciones Militares de Seguridad Civil (ComForMisc). Dicho Mando está a cargo de todas las Formaciones Militares de seguridad civil, y también de las tres Unidades de Instrucción e Intervención en Seguridad Civil (UIISC) que existen en Francia.

Las FORMISC no tienen competencia territorial, son un refuerzo nacional tal como lo son los medios aéreos nacionales, los desminadores, entre otros actores. Entre las tareas de las FORMISC se encuentran la prevención de incendios forestales mediante la quema y limpieza de zonas vulnerables; el funcionamiento del Centro de Operaciones Interdepartamentales para la Gestión de Crisis (COGIC) del Ministerio del Interior, entre otras. Estas unidades reúnen a unos 1.500 hombres, que en caso de un desastre que exceda las capacidades de un departamento o zona de defensa y seguridad, están a las órdenes del comandante de las operaciones de rescate.

El caso de España también muestra la creciente cooperación civil-militar en la GRD, en este país el equivalente de la ONEMI es la Dirección General de Protección Civil y Emergencias, organismo dependiente del Ministerio del Interior y centro neurálgico del Sistema Nacional de Protección Civil, cuyo vértice es el ministro del Interior. En este país, mediante acuerdo del Consejo de Ministros del 7 de octubre de 2005, siguiendo el modelo de las Formaciones Militares de Seguridad Civil (FORMISC), se creó la Unidad Militar Especializada (UME) ${ }^{31}$. Esta unidad interviene en cualquier lugar del territorio nacional en apoyo al Sistema Nacional de Protección Civil, a petición de las autoridades

30 GRUPOSOCIALYEMPRESARIALDELADEFENSA.¿QuéesGESD?Disponibleenlínea:https://www.gsed.gov.co/ $\mathrm{irj} /$ portal/GSED/contenido? NavigationTarget=navurl://4b5053d012fb3a8b3aea254dd0a42a63\&guest_ user=Guest_GSED

31 MINISTERIO DE DEFENSA DE ESPAÑA. Real Decreto 416/2006, del 11 de abril de 2006, que se establece el procedimiento para la organización y el despliegue de la Fuerza del Ejército de Tierra, de la Armada y del Ejército del Aire, así como de la UME. 
políticas de la zona jurisdiccional afectada por alguna emergencia de gran envergadura. Con la institucionalización de una fuerza especializada en la intervención en desastres y catástrofes; por lo tanto, España se ha preparado para intervenir en situaciones que sobrepasan las capacidades de los entes locales para hacer frente a distintos tipos de calamidades con los recursos de la defensa nacional ${ }^{32}$.

\section{LA DEFENSA EN LA GESTIÓN DEL RIESGO DE DESASTRES EN CHILE}

Cabe destacar aquí el marco legal que rige la participación de las FF.AA. en la GRD, con miras a identificar sus raíces históricas, fortalezas y debilidades actuales, con la finalidad última de identificar espacios en los cuales la Defensa Civil podría, eventualmente, contribuir a fortalecer dicha participación, y de paso también la percepción ciudadana acerca de las instituciones de la defensa. La primera normativa que crea una conexión entre el mundo militar y la GRD es la Publicación N³4 de 1964 del Servicio Hidrográfico y Oceanográfico de la Armada de Chile (en adelante, SHOA), que dispone las "Instrucciones Generales sobre el Funcionamiento del Sistema Nacional de Alerta de Maremotos". Posteriormente, a través del Decreto Supremo N 26 de 1966, del Ministerio de Defensa Nacional se designó al SHOA como el organismo representante del país ante el Pacific Tsunami Warning Center (PTWC). El mismo decreto dispuso la creación de un Sistema Nacional de Alerta de Maremotos (SNAM), encabezado por el SHOA, que tiene la responsabilidad exclusiva de difundir alertas y/o alarmas de maremotos.

La Ley $N^{\circ} 16.282$ de 1965, que fija disposiciones permanentes para casos de sismos o catástrofes, constituye una piedra angular en la reconstrucción histórica del marco regulatorio en el que ocurre la intervención de las FF.AA. en el ámbito de la GRD. Dicha ley, promulgada por el Ministerio de Hacienda, fija las disposiciones para que, en caso de producirse en el país sismos o catástrofes que provoquen daños considerables a las personas o a sus bienes, el Presidente de la República pueda decretar una zona afectada por catástrofe. La misma idea es recogida por el artículo 41 de la Constitución Política de 1980, que establece que, una vez declarado el estado de catástrofe, las zonas afectadas quedan bajo la dependencia inmediata del Jefe de la Defensa Nacional que sea designado por el Presidente de la República. De acuerdo con la norma, éste último asumirá la dirección y supervigilancia de una determinada área afectada por una catástrofe, con las atribuciones y deberes que la ley señale.

La Ley N 18.415 de 1985, que establece la Orgánica Constitucional sobre Estados de Excepción Constitucional, es otro de los pilares normativos sobre los que se basa la intervención de las FF.AA. en desastres y catástrofes, y complementa lo que el Artículo 41 de la Constitución deja sin definir. De acuerdo a dicha ley, en una situación de emergencia, y en caso de verse sobrepasadas las capacidades de las autoridades para proveer el orden y la seguridad pública, se podrá declarar un Estado de Excepción Constitucional, que implica que los derechos que la Constitución Política de la República garantiza a los chilenos pueden verse afectados, bajo ciertas condiciones y límites preestablecidos. De acuerdo a la norma mencionada, existen cuatro tipos de Estado de Excepción Constitucional: de Asamblea, de Sitio, de Emergencia y de Catástrofe. La norma en cuestión establece que,

32 SIERRA Méndez, José. Loc. Cit. 
de ser declarado el Estado de Excepción Constitucional por catástrofe, las facultades conferidas al Presidente de la República podrán ser delegadas, total o parcialmente, en los Jefes de la Defensa Nacional que él designe.

El artículo № 7 de la Ley sobre Estados de Excepción Constitucional, establece que durante el estado de catástrofe el jefe de la Defensa Nacional que se designe tiene una serie de deberes y atribuciones. Ante todo, éste debe asumir el mando de las Fuerzas Armadas y de Orden y Seguridad Pública que se encuentren en la zona declarada en estado de emergencia; controlar la entrada y salida de la zona y el tránsito en ella; dictar medidas para la protección de las obras de arte y de los servicios de utilidad pública, centros mineros, industriales, entre otros; ordenar el acopio, almacenamiento o formación de reservas de alimentos, artículos y mercancías y controlar la entrada y salida de éstas; determinar la distribución o utilización gratuita u onerosa de los bienes referidos; establecer condiciones para la celebración de reuniones en lugares de uso público; impartir directamente instrucciones a todos los funcionarios del Estado, de sus empresas o de las municipalidades que se encuentren en la zona; difundir por los medios de comunicación social las informaciones necesarias para dar tranquilidad a la población; dictar las directrices e instrucciones necesarias para el mantenimiento del orden en la zona afectada, entre otras.

La participación de las FF.AA. en el SNPC, de acuerdo con las disposiciones legales vigentes, debe ocurrir en toda etapa del ciclo de gestión del riesgo, es decir tanto en la prevención, mitigación y preparación, como en la respuesta y rehabilitación. Dicha participación se debe materializar tanto en el marco de los CPC como de los COE en todos los niveles políticos (nacional, regional, provincial y municipal). A nivel del CPC Nacional, se observa la participación del subsecretario de Defensa, de delegados institucionales (Ejército, Armada y Fuerza Aérea) y del Jefe del Estado Mayor Conjunto. A nivel de los CPC regionales, provinciales y municipales, en cambio, está predispuesta la participación de delegados institucionales y de guarniciones de las FF.AA. La participación de la defensa a nivel regional también ocurre a través del nombramiento de Autoridades de Enlace Regional, que acompañan a los Comandantes guarnicionales de las distintas unidades de las FF.AA.

Se destaca la importancia de las Autoridades de Enlace Regional, personificadas por oficiales generales o superiores de la más alta jerarquía militar y designadas por el MDN en cada una de las regiones del país. Esta figura se crea en el Plan de Emergencia y Protección Civil, con la misión de recopilar y centralizar la información relacionada con la intervención de las Fuerzas Armadas en una emergencia en sus respectivas regiones. En palabras del vicealmirante Romero, ex Jefe del Estado Mayor Conjunto de Chile: "Considerando que en estado de normalidad constitucional, ante emergencias y/o catástrofes originadas por fenómenos naturales y/o antrópicos, el ejercicio de la autoridad se desarrolla sobre el eje del gobierno interior, radicando el control de la situación en esas autoridades, la planificación militar existente está destinada a coordinar bajo la autoridad de los respectivos mandos institucionales, el empleo descentralizado, sucesivo y/o simultáneo, de los medios de las fuerzas armadas en apoyo a la autoridad. Es en ese contexto, y de acuerdo con la magnitud y localización de la catástrofe, en parte o en gran porción del territorio nacional, es que el plan recoge las previsiones de cada una de las instituciones, 
para enfrentar la emergencia y recuperar, lo más rápido posible, el estado de normalidad en las zonas afectadas" ${ }^{\prime \prime 3}$.

\section{6. ¿CÓMO FORTALECER A LA DEFENSA CIVIL PARA QUE REALICE UN APORTE MÁS CONTUNDENTE EN EL MARCO DEL SISTEMA NACIONAL DE PROTECCIÓN CIVIL?}

Tras la revisión de la trayectoria histórica y de la situación actual de la Defensa Civil, del funcionamiento del SNPC en Chile, del marco en el cual se desenvuelven las FF.AA. en dicho sistema, así como de la manera en que otros países organizan el desempeño de las funciones de protección civil, es posible apreciar la importancia que reviste la Defensa Civil como "actor capilar" y aliado local de las FF.AA. y de las autoridades políticas en situaciones de emergencia. Sin embargo, preocupa la debilidad de que caracteriza la institucionalidad de la Defensa Civil, por lo que cabe preguntarse ¿de qué manera la Defensa Civil puede transformarse en un aliado local capaz de realizar un aporte más contundente al SNPC? Esta pregunta surge a partir de lo analizado en la primera sección de este trabajo, que da cuenta de las múltiples problemáticas que aquejan a la Defensa Civil, y que la convierten en un apéndice del MDN. Como se ha comentado, en virtud de varias limitaciones (presupuestarias, legales e institucionales), la Defensa Civil actualmente se reduce a un "voluntariado obligado" por parte de aquellos jóvenes que deciden no realizar el servicio militar y desean quedar con su situación militar al día, y que además está "pasado de moda" para aquellas personas que desean prestar ayuda de algún tipo, si se considera que existen voluntariados que pueden resultar más atractivos.

De acuerdo con fuentes de la Defensa Civil, el problema principal de la organización es que el cumplimiento de su misión está supeditada al voluntarismo ${ }^{34}$. En la práctica, esto significa que no hay un número fijo, predecible y suficiente de voluntarios con los que se pueda contar en caso de que ocurra una emergencia. En otras palabras, para superar la crisis actual habría que aumentar el grado de institucionalización de la Defensa Civil. Para poder aumentar el número de voluntarios, la organización debería poder brindarles garantías mínimas, tales como un seguro médico y de vida, además de un fuero laboral para poder ausentarse del trabajo en caso de tener que atender una emergencia. Para institucionalizar la Defensa Civil también habría que dotarla de una planta de funcionarios propia, para que los Jefes de local, por ejemplo, no sean voluntarios sino funcionarios de la administración pública que respondan a las responsabilidades de su cargo. Una de las posibles soluciones a estos problemas sería la creación de una ley que equipare la Defensa Civil a los Bomberos de Chile, para que ésta llegue a ser una institución más atractiva y que cuente con un presupuesto y, consecuentemente, un número más elevado de voluntarios.

Bomberos de Chile constituye un buen ejemplo de institucionalización de una iniciativa popular, que en el pasado también pasó por momentos difíciles. Dicha institución tiene sus orígenes en el incendio en Valparaíso de 1850, tras el cual los vecinos porteños decidieron organizar el primer Cuerpo de Bomberos de Chile. De esta forma se establecieron diversos cuerpos y compañías de bomberos a lo largo y ancho del país.

33 EMCO. Concluye mayor ejercicio de apoyo ante emergencias y desastres. Disponible en línea: http://www. emco.mil.cl/?p=1060

34 Entrevista al ex Director General de la Defensa Civil de Chile, coronel de Ejército Rodrigo Vásquez Islas (2018). 
A finales de los años sesenta la situación financiera de la mayoría de estos cuerpos se tornó crítica, lo que derivó en una carencia de carros y equipamiento, lo cual produjo una pérdida de motivación para la captación de nuevos voluntarios ${ }^{35}$. Producto de esta situación se convocó a los bomberos del país, cooperaciones privadas autónomas e independientes, a agruparse en 1970 en La Junta Nacional de Bomberos, una corporación de derecho privado y de utilidad pública dependiente de la Subsecretaría del Interior. Esta organización, hasta nuestros días, es la encargada de coordinar y representar frente a las autoridades del país a los diversos cuerpos de bomberos existentes.

Con el objetivo de profesionalizar y capacitar a sus voluntarios, el 1 de junio de 1988 se fundó la Academia Nacional de Bomberos de Chile (ANB), institución cuya función principal es la formación y capacitación de su personal, junto con la docencia, investigación y extensión en todas las materias relacionadas con las actividades bomberiles. La Junta Nacional cuenta con un presupuesto de 47 mil millones de pesos, por medio de la Ley de Presupuesto de la Nación ${ }^{36}$. No obstante, este presupuesto no alcanza para cubrir todos los gastos operativos de los cuarteles. Bomberos de Chile también cuenta con financiamiento de los gobiernos regionales y municipales (de carácter voluntario de cada administración), aportes privados y campañas para recaudación de fondos. Estos aportes varían en el tiempo y de lugar en lugar.

En 2007 se creó el Plan Estratégico de Bomberos de Chile, con el objeto de generar una modernización institucional, mejorar la planta administrativa especialmente a nivel de las necesidades de los cuerpos y compañías de bomberos del país. Este plan define procesos institucionales críticos a mejorar y reforzar, tales como la formación, la asignación de recursos y materiales, la captación y rendición de recursos del Estado, la relación con organismos técnicos del Estado, la gestión de comunicaciones, y la coordinación nacional de la respuesta ${ }^{37}$. De la misma forma, en 2012 se promulgó la Ley Marco de Bomberos de Chile № 20.564 que entabla la normativa legal de bomberos y estipula, entre otras cosas, la existencia de un registro nacional de voluntarios actualizada mensualmente; la inscripción en este registro es obligatoria y de esta forma se garantiza el acceso a los beneficios de la institución y otras leyes que se contemplen a favor de bomberos ${ }^{38}$.

Junto con la falta de institucionalización, la Defensa Civil sufre de una escasa visibilidad a nivel central. Llama la atención que no esté previsto que el Director General de la Defensa Civil participe del COE Nacional. Para que la Defensa Civil sea reconsiderada en sus funciones, siempre debería integrar el COE Nacional, y no limitarse a estar presente en los COE a nivel regional y local. De acuerdo a fuentes de la Defensa Civil, la razón

35 BOMBEROS DE CHILE. Video institucional versión 2016, min 1:17 Disponible en: https://www.youtube. com/watch?time_continue $=193 \& v=0$ vawnxsylz4

36 MINISTERIO DEL INTERIOR. Proyecto de Ley de Presupuestos 2020. Disponible en línea: http://www. dipres.gob.cl/597/articles-193833 doc pdf.pdf

37 BOMBEROS DE CHILE. Planificación estratégica. Disponible en línea: http://www.bomberos.cl/ planificacion-estrategica

38 BIOBíO CHILE. Los respaldos legales que tienen bomberos para acudir a emergencias y no perder su trabajo. Disponible en línea:

https://www.biobiochile.cl/noticias/nacional/chile/2017/02/01/los-respaldos-legales-que-tienenbomberos-para-acudir-a-emergencias-y-no-perder-su-trabajo.shtml 
por la cual, en la actualidad, se justifica la ausencia del Director General de la Defensa Civil de Chile en el COE Nacional es que en dicha instancia se juntan las instituciones que realmente importan, los ministerios, por un lado, y las FF.AA., cuyo despliegue se hace efectivo en menos de 24 horas, por el otro ${ }^{39}$. Sin el ánimo de quitar los méritos a la capacidad de respuesta rápida que caracteriza a las FF.AA., se hace hincapié en la utilidad de los recursos humanos y telecomunicaciones con los que cuenta la Defensa Civil, que bien podrían aportar al monitoreo del desarrollo de una situación de carácter catastrófico y a la realización de un diagnóstico fidedigno de la magnitud de ésta, que corresponde a la tarea más importante durante las primeras 48 horas tras su ocurrencia.

Otro escenario que posibilitaría el fortalecimiento de la institucionalidad y la eficacia de la Defensa Civil de Chile es la institucionalización de la metodología estadounidense de los CERT. Se trata de centros comunales de respuesta a la emergencia, cuya versión adaptada a las necesidades del país ya ha sido implementada por la ONEMI en diversas ocasiones, con la finalidad de formar voluntarios de acuerdo con dicha metodología, basada en el "aprender haciendo". La factibilidad de esta idea reside en la creación de un plan cuadrante, en el marco del cual los centros comunitarios de emergencia a nivel comunal operen financiados por las municipalidades. Estas últimas serían las responsables de pagar el sueldo del responsable de cada centro comunitario, integrados por los voluntarios de la Defensa Civil de Chile.

Para concretar dicho plan se necesita encontrar una fórmula estandarizada para remunerar a los coordinadores municipales de emergencia, ya sea a través de Centros u Oficinas Municipales de Emergencia. Esto no necesariamente implica un gasto adicional para las municipalidades, y permitiría crear lazos de mayor compromiso entre los voluntarios de la defensa civil y las municipalidades. El problema es que, en la actualidad, no todas la municipalidades cuentan con Oficinas de emergencia, ya que en muchos municipios el tema de las emergencias es asumido por las Oficinas de seguridad ciudadana.

Un ulterior problema a resolver se relaciona con la resistencia que produce la extracción militar de los Jefes de local, que son los responsables del patrimonio de cada una de las sedes, y además representan a la Defensa Civil en los COE comunales y regionales. Actualmente, el cargo de los oficiales destinados como Jefes de local es fuente de debate: ¿Por qué un uniformado tendría que hacerse cargo de la defensa civil en una determinada zona? Si bien la idea compartida por muchos en el ámbito de la defensa es que no existan uniformados a cargo de las Sedes locales, hay que considerar las ventajas de que dicho cargo sea ocupado por un militar y no por un civil.

La primera ventaja es que si quienes están a cargo de las Sedes locales son militares no sería necesario impartirles cierto grado de uniformidad, valores y principios compartidos, porque ya responderían a la lógica jerárquica de sus respectivas instituciones de procedencia. La segunda ventaja es que el sector de la defensa, que está cada vez más involucrado en la prevención y respuesta a las emergencias, contaría con personal de las tres ramas de las FF.AA. esparcidos uniformemente por el territorio nacional, pudiendo en cualquier momento obtener información pormenorizada y en tiempo real de lo que ocurre

39 Entrevista. Loc. Cit. 
en los territorios, lo que potenciaría fuertemente el rol que las FF.AA. están llamadas a cumplir en la fase de preparación y prevención.

Otra estrategia posible para fortalecer a la institucionalidad de la Defensa Civil sería definir una serie de funciones específicas, que complementen a la función de la defensa nacional cuando las FF.AA. no entran en acción porque la emergencia en cuestión no califica como Estado de Excepción Constitucional por catástrofe. En otras palabras, se trataría de que una Defensa Civil institucionalizada y fortalecida sea el organismo a cargo de aquellas situaciones que preceden el Estado de Excepción Constitucional. Esta idea se concretaría convirtiendo a la Defensa Civil en el organismo que se haga cargo, bajo las orientaciones de las Oficinas regionales de la ONEMI, de emergencias o catástrofes de alcance regional, en coordinación interagencial con organismos tanto públicos como privados. Para ello la Defensa Civil se beneficiaría del fortalecimiento de pilares como el direccionamiento de personas (habilitación de vías de evacuación, albergues y centros de acopio), y de la delegación de otras tareas, como los primeros auxilios -que están más en la línea de la Cruz Roja, que tiene la ventaja de contar con el respaldo y financiamiento de una organización internacional- a organismos más especializados en la atención en salud.

Para lograr el fortalecimiento de la colaboración entre la Defensa Civil y las Oficinas regionales de la ONEMI en el marco del SNPC, además, se estima conveniente incentivar el trabajo comunitario a través de campañas, pasando por el potenciamiento del área de relaciones públicas de la Defensa Civil, por la participación en eventos masivos y por la elaboración de una estrategia comunicacional que apunte a destacar el valor de la cooperación civil-militar en la GRD. Otro punto para destacar es que la ONEMI siempre y solo coordina, mientras que una multiplicidad de actores ejecuta el trabajo de rescate, reconstrucción y restablecimiento de una situación de normalidad en una zona afectada por una emergencia. Sin embargo, en la actualidad no hay ningún tipo de planificación conjunta previa, sino que las coordinaciones son realizadas por la ONEMI en el momento y dependiendo de los recursos humanos y materiales a disposición en la zona afectada.

Un último asunto relevante es que existen distintas visiones y escenarios posibles con respecto a la posición de la Defensa Civil en los intersticios del Estado. Mientas que algunos creen que debería ser sacada del organigrama del MDN, y ser puesta bajo el paraguas del Ministerio del Interior y Seguridad Pública o de la misma ONEMI, en este trabajo se aboga por el mantenimiento del lugar que la Defensa Civil ocupa en la actualidad, en seno al MDN. Sin embargo, como se ha destacado, no tiene ningún sentido mantener viva la institución en las condiciones actuales, siendo que podría aportar de distintas formas al fortalecimiento del SNPC y a la institucionalización de la compenetración civilmilitar en la GRD. Para desentrampar la situación, lo ideal sería contar con un incremento presupuestario y con una ley que ampare el trabajo de los voluntarios. Mientras tanto, lo que se puede hacer ya se ha comentado en este apartado.

\section{CONCLUSIONES}

Este trabajo ha tratado de dilucidar los problemas que, en la actualidad, aquejan a la Defensa Civil y que le impiden maximizar su aporte al SNPC y profundizar el grado de compenetración civil-militar en la GRD. Habiendo revisado la trayectoria histórica de dicha 
organización y el marco legal de la GRD en Chile, destacando el rol que cumplen las FF.AA. en dicho ámbito, para concluir se aboga por el fortalecimiento de la institucionalidad de la Defensa Civil a través un aumento presupuestario y de una modernización del marco legal. De no ser viables los cursos de acción mencionados, se han señalado algunas maneras a través de las cuales la Defensa Civil podría, de igual forma, mejorar su eficacia. Se vuelve a destacar la importancia del trabajo comunicacional y de la planificación previa y conjunta con la ONEMI para potenciar la presencia de la defensa en situaciones que catalogan como Estados de Excepción Constitucional, pero también en otras situaciones que puedan beneficiarse de los recursos humanos y materiales de la defensa.

\section{REFERENCIAS BIBLIOGRÁFICAS}

BIOBÍO CHILE. Los respaldos legales que tienen bomberos para acudir a emergencias y no perder su trabajo (2017). Disponible en línea: https://www.biobiochile.cl/noticias/ nacional/chile/2017/02/01/los-respaldos-legales-que-tienen-bomberos-paraacudir-a-emergencias-y-no-perder-su-trabajo.shtml

BOMBEROS DE CHILE. Planificación estratégica. Disponible en línea: http://www. bomberos.cl/planificacion-estrategica

BOMBEROS DE CHILE. Video institucional versión 2016, Disponible en línea: https://www. youtube.com/watch?time continue $=193 \& v=0$ vawnxsylz4

CÁMARA DE DIPUTADOS DE CHILE. Proyecto de Ley que Establece el Sistema Nacional de Emergencia y Protección Civil y crea la Agencia Nacional de Protección Civil (2011), Proyectos de ley en tramitación. Disponible en línea: https://www.camara.cl/pley/ pley detalle.aspx?prmID=7940

DEFENSA CIVIL DE CHILE (Consultado 2 noviembre de 2018). Historia de la Defensa Civil de Chile, disponible en línea: https://www.defensacivil.cl/historia/

DEFENSA CIVIL CHILE. Cuenta pública (2017) Disponible en línea: http://ketchconsulting. com/2015/02/05/increased-fema-budget-part-of-presidents-2016-proposal/

DEFENSA CIVIL. Cuenta Pública 2019 completa, disponible en línea: $\quad \underline{\text { https://issuu. }}$ com/defensacivildechile1/docs/0 cuenta_publica_2019_completa.1

DEFENSA CIVIL COLOMBIANA (22 marzo 2016). Misión y Visión. Disponible en línea: https://www.defensacivil.gov.co/index.php?idcategoria=145

DEFENSA CIVIL COLOMBIANA (1 de noviembre de 2018). Ejecución presupuestal: Disponible en línea: https://www.defensacivil.gov.co/index.php?idcategoria=2389

DEFENSA CIVIL CHILE (2008). Ministerio de Defensa Nacional Programa de instrucción y entrenamiento para las sedes locales

EMCO (Consultado de noviembre de 2018). Concluye mayor ejercicio de apoyo ante emergencias y desastres. Disponible en línea: http://www.emco.mil.cl/?p=1060 
EMOL. Con críticas a Bachelet ejecutivo firma proyecto de Agencia Nacional de Protección Civil. Disponible en línea:

https://www.emol.com/noticias/nacional/2011/02/22/466119/con-criticas-abachelet-ejecutivo-firma-proyecto-de-agencia-nacional-de-proteccion-civil.html

FEMA. About the Agency. Disponible en línea: https://www.fema.gov/about-agency

GRUPO SOCIAL Y EMPRESARIAL DE LA DEFENSA, ¿Qué es GESD? Disponible en línea: https://www.gsed.gov.co/iri/portal/GSED/contenido?NavigationTarget=navurl://4b5053d012fb3a8b3aea254dd0a42a63\&guest user=Guest GSED

KETCHCONSULTING (5 de febrero de 2015). Increased fema budget part of president's 2016 proposal. Disponible en línea: http://ketchconsulting.com/2015/02/05/ increased-fema-budget-part-of-presidents-2016-proposal/

MINISTERIO DE DEFENSA DE ESPAÑA. Real Decreto 416/2006, que establece el procedimiento para la organización y el despliegue de la Fuerza del Ejército de Tierra, de la Armada y del Ejército del Aire, así como de la UME. Disponible en línea: https://www.boe.es/buscar/act.php?id=BOE-A-2006-7168

MINISTERIO DE DEFENSA NACIONAL. Ley № 8.059 que crea la defensa civil de chile del 16 de febrero de 1945. Disponible en línea:

https://www.leychile.cl/Navegar?idNorma=25744

MINISTERIO DE DEFENSA NACIONAL. Ley № 20.045 Moderniza el servicio militar obligatorio (8 agosto 2005), Disponible en línea en: https://www.leychile.cl/Navegar?idNorma=241847

MINISTÈRE DE I'INTÉRIEUR. Les unités militaires de la sécurité civile (2012). Disponible en línea: https://www.interieur.gouv.fr/Le-ministere/Securite-civile/Nos-missions/Laprotection-des-personnes-des-biens-et-de-I-environnement/Les-unites-militairesde-la-securite-civile

MINISTÈRE DE I'INTÉRIEUR. Loi de modernisation de la securite civile (13 de agosto de 2004) Ley №2004-811, Disponible en línea:http://www.ifrc.org/docs/IDRL/Laws/LOI\%20 2004-811\%20du\%2013\%20ao\%C3\%BBt\%202004\%20de\%20modernisation\%20 de\%20la\%20s\%C3\%A9curit\%C3\%A9\%20civile France\%20.pdf

MINISTERIO DEL INTERIOR YSEGURIDAD PÚBLICA. Decreto $N^{\circ} 38$ que modifica el Decreto $N^{\circ}$ 156 de 2002 y determina constitución de los Comités de Operaciones de Emergencia. Disponible en línea: http://www.amuch.cl/wp-content/uploads/2017/03/Comitesde-Operaciones-de-Emergencia.pdf

ONEMI. Política Nacional para la Gestión del Riesgo de Desastres Ministerio del Interior y Seguridad Pública (Julio 2016).

ONEMI. Bases Generales para la Formación y Capacitación en Gestión Integral del Riesgo, Academia de protección Civil (2012). Disponible en línea: 
http://repositoriodigitalonemi.cl/web/bitstream/handle/2012/1752/ BasesFormacionGestionRRD.pdf?sequence $=4$

ONEMI. Decreto N¹56 Plan Nacional Instrumento Indicativo para la Gestión Integral. Disponible en línea: http://www.onemi.cl/wp-content/themes/onemi-bootstrapmaster/library/doc/plan_nacional_0_0.pdf

ONEMI. Política Nacional de Gestión del Riesgo de Desastres (2016). Disponible en línea: http://repositoriodigitalonemi.cl/web/bitstream/handle/2012/1710/POLITICA NAC 2016 ESP.pdf?sequence $=6$

OFICINA DE NACIONES UNIDAS PARA LA COORDINACIÓN DE ASUNTOS HUMANITARIOS. ¿Qué es la coordinación humanitaria civil militar de las naciones unidas? (2012). Disponible en Línea:

https://www.unocha.org/sites/unocha/files/dms/Documents/OCHA\%20on\%20 Message_Civ_Mil_vSP.pdf

PROTECTION CIVILE. Missions de securite civile (Consultado 2 de noviembre de 2018). Disponible en línea:

http://www.protection-civile.org/missions-de-s\%C3\%A9curit\%C3\%A9-civile/en$\underline{\text { bref }}$

SENADO. El proyecto que crea el Sistema Nacional de Emergencia para reemplazar a la ONEMI recibe críticas en la Comisión de Defensa. Disponible en línea: http:// senado.cl/proyecto-que-crea-sistema-nacional-de-emergencia-para-reemplazar-ala/senado/2015-10-15/153826.html

SIERRA Méndez, José. "Protección civil y Fuerzas Armadas", Instituto Español de Estudios Estratégicos, Cuaderno de Trabajo N¹65, 2013.

THE WASHINGTON POST. FEMA has 9,106 disaster assistance employees. Only 770 get federal health insurance (2012). Disponible en línea:https://www.washingtonpost. com/news/wonk/wp/2012/11/03/fema-has-9106-disaster-assistance-employeesonly-770-get-federal-health-insurance/?utm term=.e2a5830e4d01

U.S. MISSION CHILE. ONEMI y Agencia Federal de Emergencias de los EE. UU. firman acuerdo (11 octubre 2016), Disponible en línea: https://cl.usembassy.gov/es/ onemi-y-agencia-federal-de-emergencias-de-los-ee-uu-firman-acuerdo/

24 HORAS. Cómo se financian y cuanto gastan las compañías de Bomberos en Chile (2006). Disponible en línea: https://www.24horas.cl/nacional/como-se-financian-y-cuantogastan-las-companias-de-bomberos-en-chile-2148453

\section{ENTREVISTAS}

Entrevista al ex Director General de la Defensa Civil de Chile, Coronel de Ejército Rodrigo Vásquez Islas (2018). 